\title{
Resortes y objetivos de la risa en una novela satírica sevillana anti-ilustrada de 1776: El Siglo ilustrado. Vida de Don Guindo Cerezo
}

\author{
Michel Dubuis \\ Université Lumière-Lyon 2
}

CES.XVIII, núm. 23 (2013), págs. 67-80. 


\section{RESUMEN}

Se analizan las escenas de El Siglo ilustrado, panfleto anti ilustrado, en que el protagonista, D. Guindo Cerezo, es objeto de la risa de los demás personajes o ha de provocar la del lector; lo cómico llega a lo grotesco. La risa del mismo Guindo, arma de exclusión social, se vuelve contra él.

Palabras clave

Don Guindo Cerezo, sátira, Ilustración, risa, sociabilidad.

RÉSumÉ

El Siglo ilustrado est un pamphlet contre les Lumières. On analyse les scènes où le protagoniste, D. Guindo Cerezo, est visé par le rire d'autres personnages, ou doit provoquer celui du lecteur; le comique y atteint le grotesque. Le rire de Guindo lui-même, arme d'exclusion sociale, se retourne contre lui.

\section{Mots-CLÉs}

Don Guindo Cerezo, satire, Lumières, rire, sociabilité.

Recibido: 17 de mayo 2013. Aceptado: 3 de julio de 2013. 
El siglo de las Luces fue época de debates y asaltos intelectuales que no dejaron de ser también conflictos en torno a alguna forma de poder, con sus implicaciones políticas. En tales debates hubo de ser la risa un arma literaria. Lo observaremos recorriendo la novela satírica El Siglo ilustrado. Vida de Don Guindo Cerezo ${ }^{1}$, empezando por recordar las circunstancias en que apareció.

Tras los motines de abril de 1766, que dieron eco en varios puntos de España al «motín de Esquilache», la política reformadora autoritaria del rey Carlos III y sus ministros suscitó aún reacciones bastante vivas aunque tomaran caminos de rodeo. Ejemplo de ello es la caída de Olavide, asistente de Sevilla desde 1767, hombre de confianza de Campomanes y Floridablanca, denunciado ante la Inquisición por varios motivos: declaraciones temerarias, uso de libros prohibidos o de grabados supuestamente lascivos. Le llama el rey a Madrid a fines de 1775 pero no es encarcelado antes de fines de 1776.

En Sevilla, desde la primavera de ese año, va difundiéndose aquella novela satírica y burlesca, que el autor y narrador llama «historia» y en la que el mismo Olavide se consideró aludido ${ }^{2}$. Testimonio de su éxito será el encontrarse hoy unas treinta copias, no sólo en bibliotecas de España, sino también en Francia, Irlanda o México.

Es una novela de andar bastante rápido y de tono más bien burlesco; cuenta la vida de un tal don Guindo Cerezo, cuyo nombre podría proceder de una connotación folklórica burlona de la «pera de donguindo». La proximidad de las voces «donguindo», que sugiere un nombre de personaje, y «guindo», que designa una variedad de cerezo, sugiere y proporciona al nombre «don Guindo» un apellido, «Cerezo», pero un efecto verbal cómico ha de surgir de ese injerto arborícola inesperado, si no es monstruoso ${ }^{3}$.

1 El Siglo Ilustrado. Vida de Don Guindo Cerezo por Don Justo Vera de la Ventosa. Edición crítica, estudio y notas de Michel Dubuis e Isabel Terán. México, Miguel Ángel Porrúa / Universidad Autónoma de Zacatecas / IFES.XVIII, 2010.

2 Francisco Aguilar Piñal, «Una sátira sevillana contra Olavide: la Vida de don Guindo Cerezo», Archivo hispalense, núm. 217, (1988), pág. 141. A las veinticinco copias ya enumeradas en este artículo se añadieron otras. En cuanto a las acusaciones de que fue objeto Olavide, véase un resumen en Marcelin Defourneaux, Pablo de Olavide ou l'Afrancesado (1725-1803), Paris, Presses Universitaires de France, 1959, págs. 352-353.

3 Maxime Chevalier, Quevedo y su tiempo : la agudeza verbal, Barcelona, Editorial Crítica («Filología», 24), págs. 254-255, cita un romance de Horcajo de los Montes (Ciudad Real), en que aparece un «don 
De una muy estrecha relación de su madre con un joven que solía visitarla nació Guindo en una familia acomodada e influyente en su ciudad. Sin mucho ahinco sigue estudios variados; acaba ingresando en el ejército y llega a ser gobernador de una ciudad. El narrador le califica de ilustrado, es decir que tiene afición a la vida mundana, las comidas a la francesa, el galanteo con las damas (el «cortejo»), el teatro, los bailes de máscaras y la lectura de Voltaire. La imagen del ilustrado que propone el redactor viene intencionadamente amalgamada con la de un mundano licencioso, con unos toques fuertes de anticlericalismo y de repudio a las prácticas piadosas. Las reformas que pretende llevar a cabo durante su gobierno recuerdan en parte la obra de Olavide en Sevilla ; el autor las ridiculiza y le atribuye al protagonista rasgos de impiedad para hacerle odioso además de risible. Llega a enfermar y muere en la impenitencia tras una última injusticia.

El redactor extiende a otros muchos «ilustrados» la condenación que le espera a don Guindo; sus insinuaciones en cuanto a la elección de los altos funcionarios reales bien podrían haber sido uno de los motivos que llevaron a la Audiencia de Sevilla a mandar incautar el texto y aclarar su procedencia, pero no parece que esa investigación se haya llevado a cabo ${ }^{4}$. Hoy sigue el autor disimulado bajo el seudónimo de don Justo Vera de la Ventosa ${ }^{5}$.

A lo largo del relato va pasando don Guindo por sucesivas situaciones en las que anda ostentando su temperamento egoísta, vanidoso, dominador, reacio a las obligaciones y al esfuerzo, su afición a la vida fácil, al lujo, su desprecio por los pobres, por el clero, por las obras de piedad y caridad. Sus experiencias le enfrentan con unos personajes serios a quienes enoja con sus discursos o con pobres a quienes trata mal o escandaliza. En su juventud los escarmientos que le dan le dejan en unas situaciones en las que resulta risible su humillación.

Sin embargo, las picardías del joven Guindo no provocan necesariamente la risa: de niño, insulta a sus abuelos y a los criados; en la escuela hiere a un compañero y éste resulta castigado por haberse quejado, pues no es más que el hijo de un pobre albañil (capítulos I y II). Rompiendo con el espíritu de la novela picaresca, cuyo esquema va siguiendo hasta cierto punto, bien se guarda el autor

guindo / muy cargado de avellanas», pero parece claro que no se trata de un personaje sino de un chiste sobre el nombre de una clase de peral que produce una variedad de pera grande llamada «pera de donguindo», de que hay noticia, también burlesca, en José Francisco de Isla, Fray Gerundio de Campazas, parte I, libro I, cap. VI, en la ed. de Sebold, Madrid, Espasa-Calpe, t. I, 1960 («Clásicos castellanos», 148), pág. 117. Como en el romance citado la asociación del donguindo y las avellanas, la del donguindo y el cerezo resulta heterogénea.

4 Véase Defourneaux, Pablo de Olavide..., págs. 304-305; Aguilar Piñal, art. cit., págs. 141-142.

5 Propuso Francisco Aguilar Piñal como autor (art. cit., págs. 161-162) a un religioso agustino, fray José Gómez de Avellaneda, uno de los delatores de Olavide ante la Inquisición, pero ahora, según nos dijo, le parecería hipótesis más conveniente atribuirle la autoría al jerónimo Fernando Cevallos. 
de poner a su héroe - o a su antihéroe - en situaciones en que provoque simpatía, haciéndole con preferencia ridículo u odioso. Lo que heredaría de la novela picaresca sería la función de chivo expiatorio que le impone al protagonista ${ }^{6}$.

Su propia risa, cuando se burla él de personajes que, en la perspectiva del narrador, merecen consideración, alimenta la sátira de que es objeto. Su humillación, o el desajuste entre su vanidad y su ignorancia, que ponen de manifiesto sus interlocutores, pueden provocar la risa de éstos o de otros personajes del relato, o bien, al margen del texto, tienden a divertir a los lectores. La risa del lector, cuyo resorte está en las situaciones, se sobrentiende; la de los protagonistas puede ser risa discreta («risa falsa», «modesta alegría») o bien «carcajada», «risada», o risa prolongada («se rió largamente»), con sus connotaciones, más o menos intencionadas, en el relato.

La primera ocasión de risa es el ejercicio retórico que corona los estudios de latinidad de Guindo. Su actuación al pronunciar aquella oratio podría haberse inspirado en la elocuencia del joven fray Gerundio:

Él la accionó tan bien que no le quedó por algunos días acción en el brazo derecho; le dio tanta alma que él rió, lloró e hizo cosas que, si el mismo Tulio las viera, no hay duda que llorara a moco tendido o que riera a carcajada abierta ${ }^{7}$.

Procede la comicidad de la escena de que se anteponga la gesticulación corpórea al contenido intelectual o moral que se espera de un discurso en latín. Efecto hiperbólico tiene la evocación del Orador por antonomasia, Cicerón: avala y agrava la condena por el autor de ese «siglo ilustrado» cuya inconsistencia intelectual se revela en la vacuidad mundana de una caricatura de la elocuencia y ha de resultar risible y trágica a la vez a los ojos del lector como a los del narrador.

Semejante ambigüedad, con intención de denuncia satírica, se produce en la muerte de don Toribio, el abuelo de don Guindo, al referirse el estado de ánimo de su familia: «Templaron su dolor como ilustrados y a vuelta de cada suspiro que daban por la muerte, daban una carcajada por la herencia» ${ }^{8}$.

6 Véase Philippe Rabaté, «Autoportrait du pícaro en bouc émissaire (Lazarillo de Tormes, Guzmán de Alfarache)», Les Langues Néo-latines, n 364 (mars 2013), págs. 53-76.

7 El siglo ilustrado, cap. III, ed. cit., pág. 96. Compárese por ejemplo con el sermón mudo, lib. II, cap. VI, de Fray Gerundio (ed. cit., t. II, págs. 145-146). Inspirarse en el jesuita Isla podía resultar inconfesable en aquella fecha, y aun nada conveniente, de ser el autor un regular y desarrollándose la novela satírica Fray Gerundio en un convento. Advertiría el parentesco estilístico de Don Guindo con Fray Gerundio el copista que distraídamente redactó así el título del capítulo VIII: «Muere D. Toribio, sale D. Gerundio de su Patria...» (B.N. Madrid, ms. 2583, pág. 39).

8 El siglo ilustrado, cap. VIII, ed. cit., pág. 127. 
La oposición entre esos efectos, y su gradación desde el suspiro, más discreto, a la carcajada, que no lo es, hacen de aquel supuesto luto una señal de la insensibilidad, de la codicia y la inmoralidad con las que el autor quiere identificar la ilustración.

De tal insensibilidad son ejemplo dos anécdotas en que una persona necesitada le pide limosna a don Guindo. Ya gobernador, se le acerca una joven, que quiere ser religiosa, pidiéndole una ayuda para constituir su dote: «Rióse el ilustrado caballero...» ${ }^{9}$. Como ilustrado y por tanto, como quiere el narrador, contrario a la vida religiosa, le dice a la muchacha que ya sólo da limosnas para casarse.

Más joven, al salir de un teatro en compañía de su amigo don Francolín, su introductor a los placeres de la Corte, y después de obsequiar con una rica merienda a dos mozuelas de poco recato, se les presenta un "pobre hombre necesitado de algún socorro para sustentar a su mujer y sus hijas». Le aconseja Guindo que les busque «cortejos» —o sea sigisbeos- generosos para mantenerlas. Se escandaliza el hombre ante esa desvergüenza e inmoralidad, provocando la risa de aquellos dos jóvenes privilegiados: «Riéronse los dos de sus exclamaciones, se apartaron del pobre y se encaminaron a casa de doña Cirila, donde estaban citados para la tertulia» ${ }^{10}$.

En ambos casos representan estos pobres un elemento moralmente sano en la sociedad, y éste es un tópico funcional a lo largo de la novela. Esa risa burlona de don Guindo y sus semejantes tiene que parecer escandalosa, pues acompaña posturas que rompen con los principios estoicos o ascéticos de la moral dominante y con la forma establecida de solidaridad social que era la limosna. Convendría situar el uso que se hace de esa risa en esta novela en la perspectiva de un autor que se esfuerza por confundir con la búsqueda primordial de los placeres la evolución de la sociabilidad hacia una mayor flexibilidad y una evolución ideológica que tiende a prestar valor positivo a las actividades civiles y a la vida social.

Otra ocasión de risa se presenta, que también significa mofa, pero en circunstancias distintas. En la tertulia a que aludimos más arriba, se habla de teatro. Uno de los presentes, don Emeterio, lo censura. «¿Qué halláis en la comedia», le pregunta don Guindo, como defensor del teatro, «que desdiga de la civilidad, de la humanidad, de la marcialidad y del buen gusto? ${ }^{11}$ Estos cuatro conceptos amalgaman el léxico de las aspiraciones estéticas o filosóficas de las Luces con el de la vida mundana, reunión heterogénea de criterios para enjui-

\footnotetext{
$9 \quad$ Ibíd., cap. XVII, ed. cit., pág. 181.

$10 \quad$ Ibíd., cap. IX, ed. cit., págs. 141-142.

11 Ibíd., cap. X, ed. cit., pág. 143.
} 
ciar el valor estético y moral del teatro. Don Emeterio le contesta oponiendo el verdadero sentido de estos términos con el uso que de ellos se hace para enmascarar comportamientos muy libres y perniciosos. El pasaje ha de hacer sonreír al lector con la transposición a valores inferiores de unas voces que remiten a conceptos superiores ${ }^{12}$. También manifiesta la reacción del redactor en contra de unos términos que simbolizan una evolución de su siglo hacia formas más libres y abiertas de la sociabilidad y la reflexión.

A las observaciones críticas de don Emeterio contesta don Guindo con una risa desmedida y unos comentarios burlones que le atraen la aprobación de sus oyentes:

Dio don Guindo una gran carcajada y entre varios empujones de su risa le dijo al irritado don Emeterio : «iQué lástima no uséis bigote, pera y golilla y que, hecho un nuevo don Quijote, os vayáis por el mundo a deshacer agravios !» Riéronse las damas que asistían y con su alegría pusieron alas a don Guindo para que, viéndose celebrado, siguiera motejando al pobre don Emeterio ${ }^{13}$.

Este pasaje merece algunas reflexiones:

1. ${ }^{\circ}$ La exageración de la risa que sacude a don Guindo hace de él una como máquina de reir que quita valor a sus declaraciones y justifica el enojo de su interlocutor.

$2 .^{\circ}$ La risa suele ser un acto social: es aquí un medio de que se vale una compañía de mundanos para excluir a un participante que, con una argumentación presentada como sincera, y un análisis crítico, pretende hacerles constar las trampas morales que encierra el vocabulario en que se complacen.

3. $\left.{ }^{\circ}\right)$ Ese espíritu de exclusión se concreta en dos imágenes: a) la del bigote, la perilla y la golilla, que destierran al excluido a un siglo ya pasado; b) la comparación con don Quijote, que no sólo le afecta a una empresa de otros tiempos sino que le reduce a la figura de un muñeco atareado en una operación casi mecánicamente repetida.

4. ${ }^{\circ}$ ) Esa risa de reacción de un grupo a un ataque contra sus fundamentos es risa comunicativa; despierta eco en las damas, en quienes no pa-

12 Véase Henri Bergson, Le rire. Essai sur la signification du comique, Paris, P.U.F., 233. a ed., 1967 (1. a : 1940), págs. 93-96, sobre el cómico de palabras por transposición, y especialmente por degradación. Dice don Emeterio: «Llamáis civilidad a la holgazanería y adulación, humanidad a la disolución, marcialidad a la desenvoltura y desvergüenza, y buen gusto al que aprueba todo lo pernicioso». Ed. cit., pág. 143.

13 El siglo ilustrado, cap. X, ed. cit., pág. 144. 
rece ver el autor un elemento social que aporte racionalidad y comedimiento, sino un público acogedor para el hedonismo que, a sus ojos, caracteriza el ambiente moral del siglo.

También podría observarse la connotación desfavorable de la alegría. Finalmente doña Cirila, el ama de casa, excluye a don Emeterio de la tertulia.

Una escena análoga de exclusión se produce en un banquete que ofrece la futura suegra de don Guindo por el cumpleaños de una de sus tres hijas. De sobremesa se habla de un anunciado baile de máscaras. Un tío sacerdote, don Eufrasio, advierte a los convidados de que ésa es una «ocasión próxima de muchos pecados mortales». El capitán don Guindo pretende que no es más que una inocentísima diversión, sin peligro para los «sujetos instruidos» y que se han criado con honor —es decir, probablemente, quienes se criaron en la nobleza, o como ella—. La risa de don Eufrasio apunta a la inconsciencia de don Guindo: «Gracias a Dios, dijo don Eufrasio con una risa falsa, que ya la gente que se cría con honor no tiene pasiones ni apetitos. El demonio respeta el honor [...]».

Esa risa se calificará como falsa porque el que se ríe trata con ironía un tema grave, el de la igualdad entre todos los hombres, nobles o no, aunque el orador — y, detrás de él, el autor — no considere la igualdad de derechos humanos sino la igualdad ante la tentación y la caída. La risa de don Eufrasio también acompaña una fórmula que ilustra la postura de don Guindo con una proposición inverosímil, contraria a una persuasión arraigada: «El demonio respeta el honor»; éste es otra transposición irónica, creadora de un cómico de situación — por más que esa situación parezca imaginaria-. Por fin, esa risa falsa no ha de ser risa ruidosa, sino contenida, como conviene al personaje de don Eufrasio, sacerdote.

El ama de casa, doña Aldonza, por fin rechaza las advertencias de quien contradice la opinión común al grupo de los jóvenes a quienes tiene reunidos y don Eufrasio, «abochornado», se recoge anunciando a su hermana y sus sobrinas que iban a provocar la ira de Dios. Tal amenaza, próxima al espíritu de los sermones de misión, causa hilaridad en los convidados: «Dieron muchas risadas sobre esto los bien peinados oficiales, a que correspondieron las primorosas damas, no menos alegres ${ }^{14} »$.

Multiplicadas y comunicativas, esas risadas contrastan con la risa contenida de don Eufrasio y señalan la autosatisfacción de aquellos mundanos en quienes el primordial afán por parecer se sugiere con pequeños detalles significativos: «bien peinados», «primorosas» y la falta de pertinencia de su forma de

14 Ibíd., cap. XV, ed. cit., págs. 173-174. 
pensar viene subrayada por la participación de las damas en la perspectiva poco feminista del autor y su mundillo clerical. Realzan esas risas la inconsciencia moral de aquellos mundanos. Rechazando a don Eufrasio y sus advertencias, excluyen a los propios reidores del ambiente comedido, escrupuloso, timorato, que el redactor parece concebir como el debido ambiente de una vida social dominada por la devoción y el ascetismo: podría tratarse, pues, de una risa de exclusión de doble alcance: los reidores excluyen a don Eufrasio de su mundo y se excluyen a sí mismos de una sociedad supuestamente cristiana y formal.

De hecho se dan ocasiones en que don Guindo se encuentra en una situación risible y queda rechazado del círculo de unos interlocutores que le juzgan. En su viaje hacia la Corte tiene como compañeros a un canónigo, un religioso y un caballero viejo, castellano. Guindo se entrega a sus acostumbradas declaraciones, que parecen caricaturas, con fuertes toques de anticlericalismo, de una reflexión ilustrada sobre la sociedad española: atrasos técnicos de España, mal estado de las carreteras, crítica de la vida de los religiosos regulares, ociosos y glotones. Para hacerle frente, el papel del interlocutor más dueño de sí mismo, y neutral a medias, se le da al canónigo, por tanto a un clérigo secular: si el redactor fue un regular, surge la sospecha de si habría sido ésta un recurso estratégico suyo para recurrir así, indirectamente, a la solidaridad de ambos cleros frente a un enemigo común. El canónigo le da a al joven Guindo una lección mesurada pero firme, incitándole a la lectura y a la reflexión; le reduce al silencio para lo que queda del viaje, para el mayor contento de los dos otros viajeros :

Hasta aquí habló el canónigo, a que se siguió en don Guindo un profundo silencio, en el fraile una modesta alegría y en el castellano una risa descompasada al ver confuso a Guindo sin tener qué responder ${ }^{15}$.

En la pequeña sociedad del coche, risa y alegría saludan el aniquilamiento de un disidente que profirió proposiciones disconformes, así como su extrañamiento de la conversación. En el religioso queda la risa contenida; su «modesta alegría» corresponde a lo que se espera de un sacerdote: el comedimiento (¿una forma atenuada de la gravedad?). Al seglar se le supone más libre que el clérigo en la expresión exterior de sus emociones; pues bien, su risa — «una risa descompasada»— deja atrás toda moderación cuando de «un caballero viejo» se hubiera esperado mayor gravedad, virtud tópica de un español distinguido. Su risa ha de ser pues indicio de la violencia del autor para con aquel muñeco, don Guindo, a quien quiere hacer representante simbólico de la extensión del

15 Ibíd., cap. VIII, ed. cit., pág. 136. 
pensamiento ilustrado en los sectores rectores de la sociedad española y chivo expiatorio de una evolución ideológica que él denuncia como inmoralidad..

Más violentos aún llegan a ser los malos tratos de que el redactor hace objeto a don Guindo. Éste, siendo estudiante, solía acudir a una librería en la que le gustaba estarse perorando con otros compañeros supuestamente ilustrados. Un día en que «ya se reía de la tradición, ya burlaba la sencillez de estilo de muchos de los Santos Padres», así como de la devoción popular y de los silogismos de la Escuela, le llega a oír un cura párroco, «de aspecto serio, de conversación sólida». El cura le reconviene con severidad, luego le vuelve la espalda y se va, dejándole paralizado: «[...] lo había dejado absorto y en postura de judío en estampa de Resurrección» ${ }^{16}$.

La repentina inmovilización y la asimilación a un tópico iconográfico tienden a reducir al ser humano a un objeto material, y de estas causas ha de proceder algún efecto cómico en el lector. Pero, además, la connotación de la imagen evocada implica una negación, que se sobrentiende impía, del cristianismo y lleva consigo la exclusión de la sociedad cristiana, y por tanto de la sociedad española coetánea.

Volviéndole el movimiento, Guindo sale a su vez, pero tan distraído («como iba el mozo atónito...») que no ve, a la puerta, un caballo cargado de leña; su cabellera se le enreda en una rama y se le arranca parte de ella:

No fue mayor el sentimiento que hizo la cabeza al violento impulso de desprenderse el pelo que el que hizo el corazón viendo perdido el precioso adorno que tantos cuidados le costaba ${ }^{17}$.

El cómico nace de la distracción del protagonista y del contraste imaginable entre su movimiento rápido de huida y la brusca detención al engancharse la coleta de pelo en la rama. También estará en la igual importancia que cobran el dolor moral y el dolor físico: denuncia la preponderancia de lo artificial sobre lo natural en la mente de aquel petimetre acicalado. La risa del lector ha de saludar su doble castigo: la humillación moral que le infiere quien es más sabio que él y la destrucción física de un recurso de su elegancia, es decir de un resorte esencial de su vida cotidiana y de la personalidad social a que pretende.

Otro incidente violento se produce en un pueblo en el que el flamante capitán don Guindo ha de pernoctar con su regimiento (capítulo XIII). Se aloja en casa del sacristán Bartolo, pero éste ha salido a dar aceite a las lámparas de

\footnotetext{
${ }^{16}$ Ibíd., cap. VI, ed. cit., pág. 119.

17 Ibid.
} 
la iglesia. Ahí están su mujer y su hija para acoger al huésped. Éste les espeta unas salutaciones halagüeñas y ceremoniosas de las que se estilan en la ciudad y que les infunden incomprensión y desconfianza. Luego le da por acariciar con libertad la mejilla de la muchacha, que se lo agradece con una bofetada mientras la madre le planta las uñas en la garganta. Llega en éstas el sacristán, que rompe su alcuza en la cabeza del que cree ser agresor de su familia. El elegante capitán cae al suelo cubierto de sangre y aceite.

El contraste de las formas de hablar, la incomprensión que de esta oposición resulta entre las dos pueblerinas y el figurín presumido que llega de la ciudad galleando y cortejando a las mujeres, el golpe que le tira al suelo y mancha su hermoso vestido, la calle a la que concurren luego vociferantes militares y lugareños, todo aquello podría sugerir escenas burlescas de un entremés en el que, al final, un personaje malo o ridículo se vería rechazado o castigado a palos ante las risas del público. Tan grotesco es el cómico a que llega a recurrir este panfleto novelesco que es El siglo ilustrado.

Más grotesco aún es el episodio de la muerte de don Guindo. De paso por la ciudad, años después, y enterado de que don Guindo es el gobernador, el alcalde de aquel pueblo, que lo alojó y lo curó durante su convalecencia, va a saludarle, acompañado por el mismo sacristán Bartolo. Viéndole muy enfermo, le aconsejan que se dedique a actos de piedad para no «morir como una bestia» sino como cristiano. Él se enoja, da orden de encarcelarlos, de mandarlos a presidio, hasta de ahorcarlos, pero en esto le sobreviene una crisis violenta: «Abrió don Guindo dos palmos de boca, sacó una lengua como una vaca, largó una blasfemia y con ella su alma ilustradísima» ${ }^{18}$.

La risa ha de ser el efecto de esta reducción de un sujeto humano a la animalidad mediante el rasgo hiperbolizado de la lengua, esa lengua con que don Guindo solía pecar. Al resorte burlesco se añade un alcance moral, pues con este ejemplo se demuestra lo anunciado: el impío muere «como una bestia». Así se comprueba la táctica de insistente degradación con que el autor reduce a frívolo olvido de la fragilidad humana y de la muerte, y finalmente a bestialidad, el pensamiento optimista de la Ilustración.

Merecerá atención un episodio que ilustra un eje de los ataques del autor al «siglo ilustrado»: su resistencia a los asaltos del pensamiento moderno contra la enseñanza universitaria escolástica y aristotélica. Ya bachiller en filosofía, Guindo pretende estudiar teología y lo consulta con cuatro profesores. Los tres primeros insisten en la dificultad del estudio y el esfuerzo que requiere. Se llaman don Venerando, don Modesto y don Prudencio; sus nombres, y «la cir-

18 Ibíd., cap. XVIII, ed. cit., pág. 187. 
cunspección, gravedad y juicio» que ostentan, evocan el comportamiento que se espera de unos religiosos y el respeto que se les debe. El cuarto es don Ciruela, cuyo nombre introduce en la lista de los cuatro una ruptura sorprendente y cómica: tal vez anuncie una liviandad análoga a la de su alumno don Guindo. A éste le presenta como fácil el camino de los estudios y se ríe de la severidad de sus colegas, que él explica por su vejez y su condición de frailes:

Habiéndole hecho saber Guindo el dictamen de los catedráticos al sapientísimo Ciruela, éste se rió largamente y consoló al joven diciéndole: «No extrañéis este hipocóndrico modo de pensar, muy propio de unos hombres que por su edad, por su destino y por otras mil cosas están empeñados en aguarnos todos los gustos, y tanto, que hay alguno de ellos que ha dicho que hasta el camino del cielo es difícil y otras bobadas a este modo. No tengáis cuidado, que se trata seriamente de desposeerlos de las cátedras $[\ldots]^{19}$.

En esta declaración el autor, como suele hacerlo, reduce a una opción por la facilidad, si no es por el hedonismo, una opinión, entonces difundida entre los reformadores ilustrados y que Olavide adoptó en su plan de reforma de la universidad de Sevilla: era preciso excluir a los religiosos de las universidades por ser ellos fautores de dos causas del estancamiento de la enseñanza, el escolasticismo y lo que él llamaba espíritu de partido, es decir la adhesión a las distintas escuelas filosóficas y teológicas ${ }^{20}$. Irónicamente llamado «sapientísimo», viene presentado don Ciruela como un teólogo a la violeta. Su caricaturesca enseñanza parece apoyarse en la historia eclesiástica y en la teología positiva, es decir fundada en los Santos Padres, según se deduce del uso, que se le atribuye, del Apparatus del padre Annat ${ }^{21}$. Así ha de representar tendencias modernas que rechazaría el autor, más afecto a la teología especulativa.

En el relato, se presenta don Ciruela en paralelo a su colega de filosofía, don Estupendo (¿así nombrado por ostentar su autosatisfacción?). Éste encarna en un casi ignorante la voluntad de expulsar de la Universidad a Aristóteles y a los autores escolásticos (capítulos IV y V). Sirviéndose de él para rebajar a los universitarios dispuestos a aceptar una reforma de los métodos y contenidos de la enseñanza, hace el autor que alabe, como libro de referencia, Los eruditos a

19 Ibíd., cap. VI, ed. cit., pág. 112.

20 Defourneaux, Pablo de Olavide..., págs. 118-119. Véase también: Pablo de Olavide, Plan de estudios para la Universidad de Sevilla, edic. Francisco Aguilar Piñal, Barcelona, Cultura Popular, 1969.

21 Pierre Annat, Methodicus ad positivam theologiam apparatus, 1700 y 1705. Cuenta el narrador: «Insertaba de cuando en cuando su pedazo de historia eclesiástica, que para esto tenía cuidado, antes de venir a la clase, de ver el Aparato de Annato». Ed. cit., pág. 113. 
la violeta, que Cadalso publicó en 1772 con el nombre de don José Vázquez ${ }^{22}$. Los asimila pues con unos seudosabios.

Pero si Cadalso, en Los eruditos a la violeta, se burla de los semisabios mundanos, en las Cartas marruecas, redactadas ya en 1774 pero aun no publicadas cuando se redactó El siglo ilustrado, dibuja la caricatura de un «sabio escolástico» a quien no le merecen más que risa el recurso a modelos clásicos para reformar el estilo oratorio («se echará a reir y te volverá la espalda»), los adelantos modernos de la medicina («también se reirá de ti») ni los de la física, en los que sólo quiere ver «juegos de títeres». Y si uno insiste en las ventajas que para la sociedad se derivan de los adelantos mecánicos de la física, y que ya están reconocidas en «todo el universo culto», peor será, pues «te llamarán hereje ${ }^{23}$.

Ya había recurrido Feijoo a la burla a expensas de aquellos escolásticos — colegas suyos algunos tal vez- que, sin saber casi nada de la filosofía cartesiana, le atribuían a Descartes todas las novedades de la física moderna y las rechazaban «con desprecio y risa» ${ }^{24}$. Cuenta cómo, en una tertulia, un maestro aristotélico, que se había burlado de Descartes, se había visto acosado a preguntas, a las que resultó incapaz de contestar, por un caballero seglar muy instruido en ambas filosofías, escolástica y moderna, y había quedado en ridículo. Feijoo da como hecho consumado el que, donde no se aceptaba el debate razonado y crítico (el «desengaño»), había sido la burla, que les devolvían los físicos modernos a los defensores del aristotelismo, la que los había hecho retroceder:

Mas al fin éstos mismos, o desengañados o corridos de la irrisión que hacían de ellos los desengañados, fueron cediendo poco a poco y vino a quedar enteramente libre el campo a la filosofía experimental ${ }^{25}$.

La conclusión que se podría sacar de estas líneas de Feijoo, escritor polemista y optimista a la vez, es que habría sido pues la risa un arma psicológica determinante para ganarse un público en el conflicto entre los promotores de las luces y los defensores del inmovilismo.

En El siglo ilustrado, a la inversa, la risa prolongada del seudoteólogo don Ciruela podría ser caricatura de esa risa de los filósofos modernos, críticos para

22 Véase nuestro artículo: «Des Eruditos a la violeta à la Vida de don Guindo Cerezo», en Philippe Meunier et Edgard Samper, éd., Mélanges en hommage à Jacques Soubeyroux, Saint-Étienne, Éditions du CELEC, 2008, págs. 141-153.

23 José de Cadalso, Cartas marruecas, c. a LXXVIII, edic. de Joaquín Arce, Madrid, Cátedra, 1990 («Letras Hispánicas», 78), págs. 271-273.

24 Benito Jerónimo FEIjoo, «Lo que sobra y falta en la física», Teatro crítico universal, t. VII (1736), disc. XIII, § VIII, núm. 24.

${ }_{25}$ Ibíd., § X, núm. 30. 
con el aristotelismo y la escolástica. Esa risa prolongada («se rió largamente»), risa de exclusión por parte del reidor, en realidad denuncia su autosatisfacción y su malignidad. ¿Pretendería el autor de este panfleto volver contra los modernos el arma literaria de la risa? ¿Procuraría así también dar nuevo ánimo a su propio campo?

Resulta tentador mirar este escrito como un intento vengativo, si no es desesperado, por cortar el paso a unas tendencias ya dominantes en los medios más activos de la sociedad española. La coyuntura podía parecer favorable cuando el caso Olavide demostraba un retroceso de la administración real reformadora ante la Inquisición. Amenazado en sus posiciones universitarias, el clero regular, por lo menos en sus franjas más resentidas, podía alegrarse viendo reducidos a caricaturas a aquellos competidores suyos seculares que habían apoyado la reforma de la universidad de Sevilla.

El siglo ilustrado es una novela viva e inventiva en sus episodios y en su expresión. En ella, por su carácter de panfleto, la risa, lejos de ser expresión de felicidad y alegría en sociedad, tiende a ser arma reductora y de exclusión, así como denunciadora de una desviación del juicio moral en aquel que se ríe sin medida, o en la víctima de su risa; el cómico deriva hacia lo grotesco y la violencia. Estos rasgos pueden haberla hecho más sugestiva para un lector acampado en las mismas posiciones ideológicas que su redactor. Mirada con la distancia del tiempo, da testimonio del apasionamiento y acritud de la polémica contra la Ilustración, las reformas, y la evolución de la vida social. 